\title{
DEFINICIONES IDENTITARIAS Y CONFLICTIVIDAD EN LA EDAD MEDIA. LAS RELACIONES DE FRONTERA ENTRE LOS REINOS CRISTIANOS DE MURCIA Y VALENCIA EN LOS SIGLOS XIII-XVI ${ }^{1}$
}

\author{
DEFINITIONS OF IDENTITY AND CONFLICT IN THE MIDDLE AGES. \\ FRONTIER RELATIONSHIPS AMONG THE KINGDOMS \\ OF MURCIA AND VALENCIA IN THE $13^{\text {TH }}-16^{\text {TH }}$ CENTURIES
}

Resumen: Mientras que buena parte de los estudios sobre la frontera en la Edad Media en la Península Ibérica se han centrado en las relaciones de frontera entre los reinos cristianos y el Islam, las relaciones de frontera entre los reinos cristianos han sido más desatendidas. Nuestro trabajo se centra en la relación entre las Coronas de Aragón y Castilla en el sureste peninsular en el momento de mayor expansión de ambas coronas y en las pugnas surgidas al calor de dicho avance. Lejos de suponer un mero elemento geográfico, la frontera representa la existencia de procesos de aculturación y formación de identidades. Es por ello que hemos encaminado nuestro estudio para entender cómo se articularon las herramientas utilizadas por las comunidades para regular el grado de aceptación de ciertos elementos culturales o la defensa de los mismos hacia los individuos del otro lado de la frontera. Ello nos da pie a mostrar una sociedad más compleja y dinámica que muestra lo difícil de mantener ideas sobre una identidad inmutable y esencialista.

Palabras Clave: frontera; Murcia; Valencia; identidad; conflictividad.

\section{JORGE ORTUÑO MOLINA Universidad de Murcia}

\begin{abstract}
The frontier is a key issue in Medieval Hispanic researche. Traditionally, scholars have pointed out the existence of a Great Frontier (Christian Kingdoms against Islam) and Minor Frontiers (among the Christians). Whereas the majority of the literature focuses on the first one, the second one been ignored or studied only from the perspective of the political and administrative fragmentation. This paper is the relationship between the Crowns of Aragon and Castile, especially in the Southeastern Peninsula region, in the peak of the territorial expansion process (13th and 14th centuries). Beyond accepting the frontier as a mere geographical concept, the borderland represents a space of acculturation and identity creation. Hence this paper treats the grade of defense of cultural issues or the acceptance of other cultures, with the modification and creation of new identity references. The existence of a complex and dynamic society allows us to refuse the idea of a identity as essential or immutable.
\end{abstract}

Keywords: borderland; Murcia; Valencia; identity; conflict.

\footnotetext{
${ }^{1}$ Agradezco sinceramente los sabios consejos y ayuda de Teófilo F. Ruiz en la elaboración del presente artículo. Asimismo, quisiera agradecer los comentarios e indicaciones de los revisores anónimos de la revista que han servido para dotar de claridad al texto.

Abreviaturas utlilizadas: AGS = Archivo General de Simancas; AMM = Archivo Municipal de Murcia; MMM = Miscelánea Medieval Murciana.
} 
1. Introducción.- 2. ¿La frontera como defensa de la identidad?.- 3. La formación de la frontera.4. La creación de una nueva identidad.- 5. Los conflictos Centro-Periferia.- 6. Conclusiones.

\section{INTRODUCCIÓN}

La frontera y la Península Ibérica en la Edad Media son dos términos que están estrechamente unidos. La existencia de la gran frontera entre Cristiandad e Islam y su enfrentamiento durante ocho siglos ha dado magníficos trabajos sobre las relaciones mantenidas entre ambas entidades, tales como procesos de transferencia cultural, la violencia generada en torno a su coexistencia, etc ${ }^{2}$. Este trabajo trata sobre el tema de la frontera y la identidad, pero, en lugar de dirigir nuestra atención hacia la lucha Cristiandad/Islam, centraremos nuestros esfuerzos en el análisis de las otras fronteras que se generaron tras la conquista musulmana del 711. Lo interesante de la pluralidad de reinos que conformaron la Península durante la Edad Media es que usaron las fronteras dentro de la cristiandad también como elementos activos e importantes para marcar identidades claras y específicas que escapaban de la homogeneidad peninsular. El análisis de la relación entre estos reinos da pie a destacar qué grado de asunción por parte de los habitantes tenía el sentirse participes de una misma realidad de pertenencia a una cristiandad amenazada por el Islam invasor. Estudiar, en vez de asumir, la identidad permitirá contextualizar los conflictos existentes entre los diversos reinos constitutivos de esa España medieval. En realidad, analizaremos un proceso de construcción de identidades, en plural, por parte de las comunidades, que nos permitirá poner en duda el "esencialismo" de cualquier nación, obligándonos a la necesaria ubicación cronológica y espacial.

Tanto el espacio como la complejidad del tema nos han hecho decantarnos, para argumentar lo expresado, por la realidad fronteriza habida entre los reinos cristianos de Valencia y Murcia en la Baja Edad Media. Nuestro estudio se limita a un arco cronológico entre los siglos XIII y XVI, obviando lo ocurrido con anterioridad en la Corona de Castilla y la de Aragón. Si bien esto nos priva de una visión general de las relaciones entre ambas Coronas, las ventajas de dicho marco temporal permiten ver que tanto Murcia como Valencia, espacios de nuestro análisis, fueron ganados al Islam siguiendo los mecanismos elaborados por unas sociedades ya plenamente cristalizadas y definidas, como eran la Corona de Castilla y la de Aragón. La rivalidad que pudiera haber surgido entre ambos reinos con anterioridad al siglo XIII no suponía un choque total de intereses como el que se produjo en el sureste peninsular. Hasta ese momento ambas poseían el sur como una reserva de tierras futuras, mientras que desde la conquista de Murcia por Castilla la situación cambiaba ya que se limitaba la expansión terrestre del reino de Valencia. Va a ser, por tanto, en el sur del reino de Valencia, especialmente en la zona conocida como la procuración de Orihuela, y el reino castellano de Murcia donde las energías de ambas Coronas se concentraron y donde podemos ver las pugnas y las estrategias por consolidar espacios a través no de acuerdos sino de la creación de identidades. En este sentido, podemos considerar las relaciones entre Murcia y Valencia como ejemplos de la definición y esfuerzos por

\footnotetext{
${ }^{2}$ Puede observarse una muestra de la ingente cantidad de estudios realizados hasta la fecha sobre la frontera en las dos extensas bibliografías generales sobre el tema recogidas en las obras de Robert BARTLET y Angus MACAY (eds.), Medieval frontier societies, Oxford, 1992; y en las actas de las sesiones de trabajo del II Seminario de Historia Medieval en Las sociedades de frontera en la España Medieval (J.A. SARASA, ed.), Zaragoza, 1993.
} 
individualizar cada uno de los reinos que constituyeron la Península Ibérica, a pesar de la defensa que se hace desde algunos sectores de un horizonte común a todas ellos y que tiende a despreciar la conflictividad que surgía de dicha coexistencia.

\section{2. ¿LA FRONTERA COMO DEFENSA DE LA IDENTIDAD?}

A nadie se escapa que la existencia de la frontera con el Islam en la Península ha servido para la creación, o para muchos la reafirmación, del sentimiento de unidad de los españoles al enfrentarse a un elemento extraño y ajeno a la realidad o identidad peninsular ${ }^{3}$. Igualmente, resulta una obviedad remarcar que historia y nacionalismo están estrechamente unidos. El origen de la historia como disciplina científica tiene lugar en el periodo de formación del Estado-nación y surge como una necesidad de éste para reafirmar su existencia y legitimidad. La definición aportada por Benedict Anderson de comunidades imaginadas para describir las nacionalidades que surgen al calor de la nueva realidad socio-política del siglo XIX sigue siendo una de las más clarificadoras hasta el momento. La nacionalidad crea una comunidad imaginada puesto que los individuos no se conocen entre sí, aunque comparten unos elementos que les permiten sentirse identificados y comulgar con ellos. Al mismo tiempo, esa comunidad es limitada ya que presenta unas fronteras finitas, aunque elásticas. Y por último, es una comunidad soberana que decide sobre su propia gobernación ${ }^{4}$. El problema de dicha definición, tal y como Anderson apunta, es que tiene su origen a finales del siglo XVIII. Se muestra como un artefacto cultural y, como tal, construido. ¿Qué ocurre entonces con períodos anteriores? Indudablemente, la construcción de tales comunidades imaginadas se realiza sobre una serie de elementos que permiten que esos individuos desconocidos entre sí puedan compartir unos mismos valores. Estos son, entre otros, una lengua común, una historia o un territorio. Sin embargo, el problema de cualquier nacionalismo es la tendencia a crear una homogeneización de los rasgos definitorios, para lo que se recurre a la defensa de una esencia atemporal que acompaña a la comunidad, que se identifica dentro de unos límites territoriales considerados casi sagrados ${ }^{5}$. Aquí es donde la historia juega un papel fundamental, ya que se recurre a ella para resaltar aquellos elementos que permiten la cohesión de los ciudadanos, obviando o mitigando aquellos otros factores que no interesan para tal fin. Por eso, afirma Josep Fontana que la historia se enseña más como la biografía de dichas realidades que como una herramienta para el estudio del entorno social del individuo ${ }^{6}$.

\footnotetext{
${ }^{3}$ José Antonio Maravall, El concepto de España en la Edad Media, Madrid, 1954, p. 266. Por su parte, Guichard, también se hace eco del problema de al-Andalus y reafirma el desarrollo por parte de los cristianos, ignorando cualquier consideración religiosa, de una reivindicación de la unidad política y territorial de la Península, que, en buena parte, dio fundamento ideológico a la Reconquista. Pierre GUICHARD, Pierre BONNASSIE y Marie Claude GERBET, Las Españas Medievales, Barcelona, 2001, p. 53.

${ }^{4}$ Benedict ANDERSON, Comunidades imaginadas. Reflexiones sobre el origen y la propagación del nacionalismo, Mexico, 1991, p. 24.

5 "The idea of the national territory is an important element of every national ideology. Every nation regards its country as an inalienable sacred heritage, and its independence, integrity, and homogeneity appear bound up with national security, independence, and honour. This territory is often described as the body of the national organism, and the language as its soul." Frank HERTZ, Nationality in History and Politics: A Psychology and sociology of national sentiment and Nationalism, London, 1944. pp. 150-151 (Citado por Peter SAHLINS, Boundaries: The making of France and Spain in the Pyrenees, Berkeley, 1988, p. 3).

${ }^{6}$ Josep FonTANA, La construcció de la identitat. Reflexions sobre el pasat i sobre el present, Barcelona, 2005, p. 20.
} 
La idea de esas comunidades culturales homogéneas desde el principio de los tiempos resulta cuestionable si nos acercamos a las propias fuentes históricas. Como ejemplo de esa conciencia constructiva de algo nuevo desde la centuria del 1800 nos remitimos a las palabras del político conservador español Antonio Alcalá Galiano que decía en 1835, en los años finales del absolutismo en la Península Ibérica, que los políticos liberales españoles pretendían hacer de España una nación, que no lo es ni lo ha sido nunca ${ }^{7}$. Ladero Quesada recoge que en las crónicas medievales, y especialmente a partir de la Baja Edad Media, existía una conciencia en la elite cultural y política del país de que España era un referente de unidad y que, como defiende el autor, no se referían tanto a un ámbito de dominio político sino sobre todo a una identidad histórica ${ }^{8}$. No obstante, existen testimonios paralelos que permiten corroborar la tesis de Anderson que demuestran que en pleno siglo XVI, junto a la lista de cronistas defensores de la unidad "nacional" llevada por los Reyes Católicos, las comunidades tenían conciencia de las diferencias y de su única vinculación entre ellas a través de la Corona ${ }^{9}$. Como era la monarquía la que servía como punto de unión de todos los súbditos, tras la desaparición de las monarquías absolutas se hizo necesario la creación de nuevos lazos de unidad y cohesión entre la comunidad. Por lo tanto, el uso del concepto nación nos obliga a su uso en un momento histórico muy determinado, momento del que todavía somos tributarios, ya que implica necesariamente una nueva necesidad surgida en el siglo XIX para desarrollar un profundo sentimiento de compenetración y obligaciones hacia la "nación" lejos de los habidos hasta ese momento. En cualquier caso, la constatación de identidades contradictorias en las fuentes medievales nos sirve para desarrollar la idea de conjunción o dinámica de identidades existentes en la sociedad que ayuda a rechazar el esencialismo identitario.

A lo largo de las siguientes páginas analizaremos el tema partiendo de unos postulados definidos por la antropología respecto a la creación de la identidad. Frente a la identidad como una esencia, lo cual implica invariabilidad, homogeneidad y permanencia, las nuevas líneas de investigación en dicha disciplina tienden a definir la identidad como consecuencia de un proceso dinámico, en el que no sólo entra en juego la definición de cultura como un ente abstracto que ha sido difícil de precisar hasta el momento ${ }^{10}$. Consideramos la identidad como la construcción de un sentimien-

\footnotetext{
${ }^{7}$ Citado por J. FonTANA, La construcció de la identitat, p. 20

${ }^{8}$ Miguel Ángel LADERo QuESADA, Ideas e imágenes sobre España en la Edad Media, en Sobre la realidad de España (F. TOMAS Y VALIENTE, ed.), p. 49. Como ejemplo, Antonio de Nebrija, protegido por los Reyes Católicos, escribía que "los miembros e pedazos de España, que estavan por muchas partes derramados, se redujeron e apuntaron en un cuerpo e unidad de Reino, la forma e travazon del cual assi está ordenada que muchos siglos, injuria e tiempos no lo podrán romper ni desatar" (Elio Antonio de NEBRIJA, Gramática de la lengua castellana, edición de Antonio Quilis, Madrid, 1989, p. 112).

${ }^{9}$ Los problemas generados por el robo de ganados entre los vecinos, y a los problemas de jurisdicciones distintas a pesar de una misma monarquía, llevó al procurador de Orihuela a lamentar los problemas habidos con el concejo de Murcia ya que éste "no aviendo acatamiento que esa dicha ciudad de Orihuela es real e de la majestad del rey, e con esta dicha çibdad [Murcia] son un señorio de un rey e señor, e que lo que mas fuerte es no tener proceso de marca, requesta e fadiga alguna directe ni yndiretamente, syn proçeder requesta de persona alguna las dichas cosas se atentaron de haser. Las quales no se tentaron en tiempo que las dichas dos çibdades heran en señorío de dos reyes" (AMM, Leg. 4282, n 26, f. 2r). Es decir, que las querellas existentes entre los dos territorios no se debían evitar por tratarse de una misma comunidad sino por tener un mismo rey al que debían servir.

${ }^{10}$ Para Pinxten y Verstraete la corriente culturalista que defiende el concepto "cultura" como eje diferenciador entre grupos o comunidades presenta una importante deficiencia en su formulación. Las dificultades para proponer un modelo científicamente adecuado son diversas: resulta imposible delimitar una cultura porque los procedimientos de préstamos entre grupos y comunidades, de guerra, de
} 
to en el que la relación entre el individuo, el grupo o la comunidad están en constante interacción ${ }^{11}$.

Las teorías sobre la construcción nacional dirigida desde el centro e impuesta sobre las periferias en un proceso de homogeneización, o la creación de la identidad nacional siguiendo el esquema de círculos concéntricos están siendo puestas a debate ${ }^{12}$. Hasta mediados de siglo se admitía que la elaboración de la identidad nacional derivaba de un proceso por el cual el individuo reemplazaba su fidelidad hacia la tierra o la aldea a favor de todo el país. Esta visión, como bien ha puesto de manifiesto Peter Sahlins, rechaza por completo las identidades locales o territoriales, y niega los papeles de las comunidades locales y grupos sociales en la formación de sus propias identidades nacionales ${ }^{13}$. En la construcción de la identidad entra en juego la paradoja en tanto que un individuo, un grupo o la comunidad en su conjunto están, a menudo, influidos, incluso guiados, por contradicciones entre ellos, estableciendo una determinación recíproca. Esta tensión entre adhesión y libertad juega un papel importante en numerosos conflictos ${ }^{14} \mathrm{y}$, lo que es importante, crea más de una identidad con la que los individuos se sienten identificados y de la que hacen uso, llegado el caso, cuando se producen situaciones conflictivas en las que sus intereses se ven amenazados. Por otro lado, la identidad es el resultado de una

matrimonio y de comercio modifican el fenómeno. Asimismo, resulta imposible identificar una cultura como un fenómeno diacrónico, lo que nos lleva, en cierta medida, a considerar la cultura como un elemento mutable, en contra del punto de vista occidental que ha negado toda dimensión histórica a las sociedades occidentales. Para estos autores, el uso del concepto analítico de cultura debería tener en cuenta entidades materiales: de personas, de grupos y de comunidades con características intrínsecas y particulares de interacciones en cada entidad. Reiteran que lo que se ha denominado "cultura" en la literatura forma parte del sistema de procedimientos de individuos, de grupos y de comunidades que pasan a llamar dinámicas de identidad. Rik PINXTEN y Ghislain VERSTRAETE, Culturalidad, representación y autorepresentación, "Revista CIDOB d’Afers Internacionals", 66-67 (2004), pp. 18.

${ }^{11}$ Distinguimos tres niveles de identidades: el individuo, el grupo y la comunidad. Son tres niveles de amplitud pero, al mismo tiempo, tres tipos cualitativos diferentes: la identidad individual concierne a cada persona en sí misma, la identidad de grupo se define por las relaciones interpersonales reales, mientras que la identidad comunitaria, en principio, trasciende en el tiempo y en el espacio a los individuos y a los grupos existentes. Ibidem, p. 14. Así mismo, afirman los autores que "el esencialismo, desde los puntos de vista sociologista y culturalista, no sobrevive al análisis científico crítico. "constatamos que los seres humanos se comprometen en la comunicación y en la interacción a través del mundo. Por lo tanto, el esencialismo bajo el aspecto del culturalismo (la extrema derecha, por ejemplo) o del sociologismo (el laicismo francés, por ejemplo) se presenta como una forma exclusiva de comunicación. Se trata más bien de un monólogo que de un diálogo o de una forma de interacción. De este modo, todo esencialismo es calificado como una posición ideológica de individuos, de grupos o de comunidades, y no como un instrumento analítico de trabajo científico.” Ibidem, p. 12.

${ }^{12}$ La teoría clásica de círculos concéntricos defiende que el individuo posee una escala de valores que va desde la propia tierra (localidad natal) hasta la nación, pasando por diversos escalones sucesivos de fidelidad (la aleda, el condado, la región, etc). En dicha teoría, la fidelidad va decreciendo conforme se aleja del epicentro del individuo. P. SAHLINS, Boundaries: The making, p. 111-112.

${ }^{13}$ P. SAHLins, Boundaries: The making, p. 8.

${ }^{14}$ Para Northrup la identidad debe operar dinámicamente desde el mismo momento en el que el sentido de identidad de uno mismo o del grupo no es estático. La propia percepción del individuo está constantemente en relación con el mundo, recibiendo información con la que debe tratar y ajustar a la propia definición de uno mismo. Cuando los hechos amenazan los principios de nuestras representaciones, el individuo o el grupo reaccionará enérgicamente para preservar dicha identidad. Es por tanto esta relación dinámica entre identidad y la interacción con el mundo uno de los principales factores en los conflictos. Cuando surge un conflicto, incluso en los casos en los que la identidad se encuentra mínimamente involucrada en la disputa inicial, la identidad personal o social comienza a verse cada vez más como argumento esgrimido por las partes. Terrell A. NORTHRUP, The dynamic of Identity in personal and social conflict, en Intractable conflicts and their transformation (L. KRIESBERG, ed.), Syracuse, 1989, pp. 55-82. 
respuesta del ser humano para la comprensión y la clasificación del mundo que lo pueda hacer predecible y habitable. Mas, al mismo tiempo, posee las necesarias capacidades para la adaptación a las circunstancias cambiantes que lo puedan hacer igual de habitable $^{15}$, lo que supone que la modificación de las circunstancias de las comunidades lleva consigo la modificación y/o la aparición de nuevos elementos constitutivos de la identidad, como puede ser la imposición de una demarcación administrativa nueva.

En definitiva, al entender la identidad como un elemento dinámico y, por tanto, cambiante, la historia juega un papel fundamental en la explicación de tales fenómenos y obliga a especificar el momento histórico para la comprensión y explicación del carácter identitario. Este hecho, que puede sonar tan obvio, es a menudo ignorado en el discurso político, y de vez en cuando académico, en aras a mantener el continuo valor universal y natural de las diversas nacionalidades contemporáneas. Por otro lado, y como comprobaremos, no todos los individuos, y esta es otra de los elementos que contradicen ese esencialismo nacional, asumían por igual su identificación con el resto de los "compatriotas". Afirmaba Caro Baroja que la formación intelectual, los recursos económicos, la esfera habitual de desplazamiento y su integración en diversos proyectos regionales, estatales, etc. establecen unos parámetros diferentes en las conciencias identitarias de cada uno de los individuos, que ha de ser tenida en cuenta para comprender el valor del mensaje ${ }^{16}$.

Las identidades cambian, nacen y desaparecen, y las elites (políticas) pueden influir en este proceso de forma crucial mediante la elaboración de unos discursos que permiten dotar de cohesión a la identidad comunitaria ${ }^{17}$. A este respecto es interesante hacer una llamada de atención sobre las fuentes utilizadas. El uso de las crónicas como único elemento para hablar de la historia de los reinos debe obligar a tener en cuenta que tales obras se redactaban para dotar de legitimidad a los intereses de la monarquía. La utilización de las crónicas y materiales elaborados desde dichas esferas ciertamente nos aporta una visión, que a nuestro entender, tan sólo es un elemento más a tener en consideración ${ }^{18}$. Pero su uso exclusivo provoca, para el caso que aquí nos ocupa, que se encubra y no se explique el valor de la frontera entre los diversos reinos cristianos y su conflictividad ${ }^{19}$. Sin embargo, si abordamos la problemática desde los diplomas

\footnotetext{
${ }^{15}$ George KELLY, Theory of Personality. The psycology of personal constructs, Nueva York, 1955, p. 105.

${ }^{16}$ Julio Caro Baroja, Razas, pueblos y linajes, Madrid, 1957, pp. 267-268.

${ }^{17}$ Más aún en una sociedad como la medieval en el que la existencia del clientelismo se convierte en una base fundamental para entender las lealtades y los compromisos comunitarios. No hablamos únicamente de los lazos feudales existentes entre las redes de poder de la nobleza, sino también a las existentes en el mundo campesino. Como afirma Enric Guinot, la aparición de familias campesinas que conforman una élite local establecía dos tipos de red clientelar: una, hacia arriba, como agentes de los nobles y señores del lugar donde viven actuando como intermediarios frente al resto de la comunidad, lo cual les permitía obtener pequeños beneficios y recompensas. Pero, por otro lado, establecían su propia red clientelar sobre sus vecinos, favoreciendo la solidaridad, pero también el control, a través del préstamo, los pequeños favores y, también, el uso del poder municipal local en su beneficio económico. Enric GUINOT RODRÍGUEZ, Oligarquías y clientelismo en las comunidades rurales del sur de la corona de Aragón (siglos XII-XV), "Hispania", 70/235 (2010), pp. 409-430.

${ }^{18}$ El goticismo, como señala Ladero Quesada, contribuyó durante siglos a mantener la noción de un denominador común histórico hispánico. Como motor ideológico, la idea de restauración de la monarquía visigoda o goticismo, fue transmitido a través de los intelectuales de la Edad Media, próximos a las cancillerías, pues muchos de ellos fueron cronistas y miembros próximos a la corte. M.A. LADERO QUESADA, La formación medieval de España. Territorios. Regiones. Reinos, Madrid, 2004, p. 55.

${ }^{19}$ En varios de los manuales de divulgación el corónimo de España aparece en plural, refiriéndose a las Españas medievales. Dicho elemento es significativo en cuanto que dentro del concepto identitario de España se reconocen otras categorías incluidas en él, obligando a dar respuesta a un fenómeno sin-
} 
elaborados por las cancillerías con motivo de las relaciones diarias entre las comunidades, es decir, pleitos, quejas, hermandades, etc. aportamos otra perspectiva que puede entrar en contradicción con la anterior. ¿Son falsas las dos visiones? ¿Entramos en un problema de relativismo? No exactamente. Nos obliga a renunciar al esencialismo como un concepto explicativo, y nos dirige hacia el análisis temporal y espacial para comprender qué tipo de identidad usan los individuos, y en función a qué intereses.

\section{LA FORMACIÓN DE LA FRONTERA}

La incorporación del reino de Murcia y Valencia a Castilla y a la Corona de Aragón, respectivamente, comenzó mucho antes de su conquista a mediados del siglo XIII. En realidad comenzó un siglo antes con el acuerdo de los monarcas aragonés y castellano de delimitar las zonas de conquistas futuras en territorio andalusí. No se trataba de perfilar los límites del reino, sino acordar qué regiones pertenecerían a cada cual en un futurible. La primera de dichas reuniones se efectuó en Tudilén en 1151. El resultado de tal encuentro otorgaba al monarca aragonés los reinos musulmanes de Valencia, Denia, Játiva y Murcia ${ }^{20}$. Obviamente, aunque no se especificara una línea clara de definición, el mero hecho de indicar la inclusión de diferentes reinos debería hacerse con la presunción de los límites que cada uno de ellos tuviera, por lo que ya se marcaba un eje espacial de actuación que concretizaba el avance cristiano y lo sujetaba a unas obligaciones espaciales. En 1179 se volvieron a reunir los monarcas en Cazola para perfilar los límites del avance que hasta ese momento se había llevado a cabo por ambas coronas (Castilla había conquistado Cuenca, y Aragón había llegado hasta Teruel). Con este nuevo acuerdo se dibujaba con una mayor precisión la línea de avance, puesto que tanto las transformaciones ocurridas en al-Andalús con la llegada de los Almohades, así como la cercanía y el avance particular de cada reino cristiano, hacía necesaria una mayor concreción. Lo que se buscó en términos generales fue una línea de separación que cabría establecer entre las estribaciones del sistema Ibérico y las septentrionales del Sistema Bético, resultante también en la divisoria de aguas entre el río Júcar y el río Segura ${ }^{21}$. Esto significaba que el reino de Murcia pasaba a la Corona de Castilla, como cambio más significativo. La expansión sincrónica de Castilla y Aragón terminó por concretarse en el siglo XIII con las conquistas de Valencia (1222-1245) por Jaime I de Aragón y Murcia (1212-1243) por Fernando III de Castilla. No obstante, y a pesar de los pactos, los deseos expansionistas de ambas monarquías terminaron por enfrentarse en forma de escaramuzas y tensión prebélica.

gular como es la pluralidad de reinos, lenguas, instituciones y enfrentamientos entre ellos en la Edad Media de la Península. En estos discursos se apostilla necesariamente que "el término pone de relieve la fragmentación política existente en el Medievo, en el espacio que había conocido, siglos atrás, el desarrollo del reino visigodo". J. VALDEÓN BARUQUE, Introducción, en Historia de las Españas medievales (J. CARRASCO, J.M. SAlRACH, J. VALDEÓN y M. J. ViguERA, eds.), Barcelona, 2002, p. 7. Mas, seguimos haciendo siempre referencia a divisiones políticas y nunca identitarias. Es, ante todo, un primer paso llevado a cabo por la disciplina histórica, que sin embargo queda encubierto aún por la falta de recursos interpretativos que otras disciplinas poseen para el análisis de conceptos como el de nación.

${ }^{20}$ Menos las ciudades de Lorca y Vera que pasarían para Castilla y que servirían de limite al reino aragonés, ya que en esos momentos Alfonso VII de Castilla se había apoderado de la ciudad de Almería y confiaba poder hacerse con todo el territorio circundante, por lo que Lorca sería la frontera con el reino cristiano vecino.

${ }^{21}$ Juan TORRES FONTES, La delimitación del sudeste peninsular. Tratados de partición de la Reconquista, Murcia, 1950. Para la evolución del reino de Valencia, Enric GUINOT RODRÍGUEZ, Els límits del regne de València, Valencia, 1995. 
Así, gran parte de los señores castellanos de la frontera intrigaban con los caudillos del reino de Valencia para que se rindiesen a Castilla y no a Aragón, cuando por acuerdo de ambas coronas en Cazola debían corresponder a esta última ${ }^{22}$. En contestación a ello, Aragón tomó para sí Villena, Sax y Caudete. La situación crispada se solventó con el acuerdo de Almizra (marzo de 1244) por el que ambos monarcas fijaron definitivamente los límites, de una manera más precisa ${ }^{23}$. En gran medida, dicha entrevista supuso la ratificación sobre el terreno de las líneas imaginarias de Cazola ${ }^{24}$.

Mas, a pesar de los pactos, la conquista de Murcia y Valencia no es tan solo resultado de un debate diplomático, sino fruto de la política de las armas y la conquista, por lo que el resultado final de su configuración no puede achacarse a meras unidades geopolíticas preexistentes que dotaran de cohesión al espacio incorporado por ambas Coronas. En el caso valenciano, estas fronteras no correspondieron a un territorio único de época islámica, sino que se reunieron reinos de taifas y gobiernos autónomos locales musulmanes que existían concretamente en el Sharq al-Andalus en esos años de la conquista ${ }^{25}$. Los límites del reino cristiano de Murcia tampoco respetaban los límites del emirato islámico. El reino de Murcia fue una creación histórica de Alfonso X que surgió del avance castellano a través de las fuerzas de las armas, de los tratados territoriales con Aragón, y como respuesta para frenar las ansias expansionistas de los concejos de Alcaraz (ciudad de realengo pero adscrita administrativamente al reino de Toledo, cuyos intereses estaban muy ligados al arzobispo de dicha sede metropolitana) y el de Alarcón (adscrito al obispado de Cuenca). El espacio ocupado por el reino de Murcia, en cierta manera por exclusión de la labor realizada por otros frentes (Granada que se apoderó del valle del Almanzora, supuestamente parte del reino de Murcia así mencionado en los acuerdos de Cazola), Aragón, caballeros de Alarcón y de Alcaraz, estuvo muy vinculado a la monarquía por tratarse de la primera conquista lograda por Alfonso X siendo aún un infante, pero los límites administrativos de esta nueva región no quedarían configurados hasta la década de 1270 frente a las otras demarcaciones y reinos vecinos ${ }^{26}$. En un intento por evitar las ansias expansionistas de las regiones vecinas sobre este espacio, también se decidió concederle una sede episcopal exenta, independiente de Toledo, Cuenca o Tarragona, lo que reafirmaría con el tiempo la unidad de dicho espacio ${ }^{27}$. En el plano administrativo, la Corona castellana decidió crear el cargo de merino mayor "de

${ }^{22}$ Fue el caso de las ciudades de Alcira, Enguera, Mogente... que se rindieron a los castellanos y no a los aragoneses. Por ello el rey Jaime I tomó represalias, llegando incluso a ejecutar caballeros castellanos que intentaban quitarle la codiciada perla de Játiva.

${ }^{23}$ Recoge el documento de la delimitación J. TORRES FONTES, Documentos del Siglo XIII en Colección de documentos para la historia del reino de Murcia, Murcia, 1969, pp. 3-4 (Codom, II)

${ }^{24}$ J. TORRES FonTES, La reconquista de Murcia en 1266 por Jaime I de Aragón, Murcia, 1987. p. 41

${ }^{25}$ Enric GUINOT RODRÍGUEZ, Fronteras exteriores e interiores en la creación de un reino medieval: Valencia en el siglo XIII, "Studia Historica. Historia Medieval”, 24 (2006), pp. 127-153.

${ }^{26}$ Momento en el que se pierde definitivamente Las Peñas de San Pedro a favor de Alcaraz, todo el sector occidental de la sierra de Segura queda para la orden de Santiago pero dentro de los límites del reino de Murcia, y momento en el cual se pierde definitivamente todo el valle del Almanzora (Vera) a manos de los musulmanes. Miguel RoDríGuez Llopis, Historia de la Región de Murcia, Murcia, 1998, pp. 76-77.

${ }^{27}$ Por la bula Spiritu Exultante del 31 de julio de 1250 se restauraba la antigua diócesis visigoda de Cartagena, aunque circunscrita a los límites del reino conquistado. J. TORRES FONTES, El obispado de Cartagena en el siglo XIII, "Hispania", 52-53 (1953), pp. 23-34. Aunque la diócesis tuvo como sede (y nombre de la misma) Cartagena en un primer momento, en 1291 la catedral y palacio episcopal se trasladaron a la capital del reino, abandonando Cartagena, aunque se mantuviera el nombre de la sede de Cartagena. 
las tierras de la conquista de Murcia”, que en palabras de Rodríguez Llopis identifica a las claras lo impreciso que resultaba el proyecto del nuevo reino. En 1258 se creó, para sustituir al merino, la figura del adelantado como representante máximo de la figura del monarca en el sureste. En él recaía la justicia en representación del rey, la administración del territorio y la organización y defensa en la frontera. Su autoridad abarcaba, teóricamente, a la totalidad del reino aunque la expansión señorial y la solidez de algunos nobles en sus señoríos fueron mermándola a partir de la siguiente centuria ${ }^{28}$.

Durante toda la Baja Edad Media el perfil del reino se verá modificado, básicamente, por la confrontación con la Corona aragonesa. La crisis política de la monarquía castellana en el último cuarto del siglo XIII debido al problema sucesorio planteado en el reinado de Alfonso X tuvo unas repercusiones trascendentales en el devenir de estas fronteras $^{29}$. En 1296 Jaime II de Aragón iniciaba la conquista del reino de Murcia con unos antecedentes que traducen a las claras la presencia e intereses de valencianos en el reino murciano. De hecho, según el cronista Ramón Muntaner, desde la entrega del reino murciano a Alfonso X por parte de Jaime $\mathrm{I}^{30}$, todos los monarcas aragoneses habían sentido nostalgia por dicho reino ${ }^{31}$. Sin embargo, la posibilidad de actuar de nuevo sobre estos territorios se presentó como un regalo gracias a la crisis dinástica en Castilla. Desde 1296 hasta 1304 parte del reino de Murcia fue ocupado por Aragón. La invasión del reino no fue total, y ocupó las zonas costeras e inmediatamente anejas a ellas, descuidando la mitad de la región que quedó en manos castellanas. Ni las tierras ocupadas por la orden de Santiago ni las que incluían las ubicadas en la Mancha (parte más septentrional) fueron objeto de pretensiones de Jaime II. La necesidad de la costa como un elemento esencial para la expansión del reino valenciano queda patente en sus objetivos militares ${ }^{32}$. Durante ocho años el rey aragonés mantuvo ocupadas las tierras del rey de castellano, aprovechándose de la debilidad en el trono del pequeño Fernando IV de Castilla, otorgando fueros al reino de Murcia similares a los otorgados para la ciudad de Valencia, por lo que intentaba crear una organización social y jurídica diferentes a las creadas por los monarcas castellanos $^{33}$. No obstante, la proclamación de la mayoría de edad de Fernando IV de Castilla en 1304, y el apoyo del papa al rey castellano en la cuestión sobre su legitimidad al trono otorgaban una cohesión al reino castellano con la que Jaime II no quería enfrentarse. Rápidamente se buscó un acuerdo a la situación y entre 1304 y 1305 se llegó a un acuerdo de paz y la retirada de Jaime II del reino de Murcia. Mas, buena parte del reino quedó en manos del rey aragonés. La parte conquistada al reino de Murcia se anexionó al reino de Valencia sin crear un nuevo reino a la unidad de la Corona aragonesa, si bien mantuvo una particularidad considerable dentro del reino valenciano. No en vano, se le denominó la procuración de Orihuela desde $1308^{34}$.

${ }^{28}$ M. RodríGUEZ Llopis, Historia de la Región de Murcia, p. 93.

${ }^{29}$ M. RodríGuez Llopis (coord.), Alfonso X y su época: el siglo del rey sabio, Barcelona, 2001.

${ }^{30}$ De Ayala piensa que la entrega posee ciertos elementos que deja entrever ciertas condiciones por parte de Jaime I a Alfonso X, como la presunta dote del reino a la infanta Constanza para su boda con el infante castellano don Manuel. Carlos DE AYALA, Jaime I y la sublevación mudéjar-granadina de 1264, en Homenaje a Juan Torres Fontes, Murcia, 1987, pp. 93-107.

${ }^{31}$ Ramón MunTANER, Crónica, cap. CCXLVI.

${ }^{32}$ M. RODRÍGUEZ LLOPIS, La expansión territorial castellana sobre la cuenca del Segura (12351325), “MMM", 12 (1985), pp. 105-138.

${ }^{33}$ Juan Manuel DEL ESTAL GuTIÉRREZ, El fuero y las “constituciones regni Murcie” de Jaime II de Aragón (1296-1301), "Anales de la Universidad de Alicante. Historia Medieval”, 8 (1990-1991), pp. 19-56.

${ }^{34}$ Juan Antonio BARRIO y José Vicente CABEZUELO, La defensa de los privilegios locales y la resistencia a la centralización política en la gobernación de Orihuela, "Anales de la Universidad de Alicante. Historia Medieval", 13 (2000-2002), pp. 9-42. 
Las relaciones conflictivas no terminaron con dicha fijación de la paz y acuerdo consensuado de los límites. Castilla no aceptó la pérdida territorial y a mediados de siglo una nueva guerra tuvo su correlato en la modificación de los límites del reino. En este caso, y tras cincuenta años de presencia aragonesa en la zona, y las medias adoptadas en el espacio como veremos más adelante, hicieron difícil el avance castellano y la anexión de nuevas tierras. Con la guerra de los dos Pedros (13561366), una de las más devastadoras y cruentas de las acontecidas entre Castilla y la Corona de Aragón, las villas de Jumilla, Villena, Sax y Abanilla revirtieron de nuevo en el reino murciano después de que durante más de un año los castellanos hubieran ocupado todas las tierras conquistadas y anexionadas por Jaime II medio siglo antes $^{35}$. El inicio de la guerra civil en Castilla frustró todos los planes de anexión definitiva del resto del territorio, dejando definitivamente los límites estables entre ambas regiones. Ya no se volverían a producir cambios en los límites entre los reinos, pero para llegar hasta esta situación habían transcurrido más de un siglo desde la incorporación del reino de Valencia y de Murcia al orbe cristiano.

\section{LA CREACIÓN DE UNA NUEVA IDENTIDAD}

Desde el momento de la conquista del reino de Murcia a mediados del siglo XIII, los monarcas castellanos utilizaron los privilegios locales como elementos de atracción poblacional. Junto a los fueros, los privilegios completaban un marco jurídico idóneo que facilitaba la residencia de los individuos a través de ventajas fiscales, comerciales y de participación en la vida ciudadana. Esto se hacía necesario ante la cercanía de la frontera con el Islam, y también con el reino de Valencia, lo que provocaba una inseguridad en la vida de los $\operatorname{colonos}^{36}$. A través de estos privilegios, y la obligación de los vecinos de residir permanentemente, o la mayor parte del año, en aquellos lugares se intentaba crear una frontera humana consolidada que convirtiese la frontera en un elemento estable. Por su parte, el rey de Aragón usaba las mismas técnicas colonizadoras. Sin embargo, la frontera que se creaba con el fin de la delimitación y diferenciación generaba unos espacios de interconexión entre las regiones fronterizas implicadas que traducían una dependencia económica regional. Estos privilegios ya demuestran una significativa diferencia entre las comunidades fronterizas y el resto de los respectivos reinos. Sin embargo, nuestra atención no se centra, de momento, en esas particularidades económicas, sino en las condiciones especiales impuestas por los poderes capaces de desarrollar nuevos sentimientos de comunidad. Estos espacios no son únicamente económicos, sino que se convierten en realidades espaciales difíciles de clasificar por parte de las cancillerías reales. Acudamos al ejemplo de la procuración de Orihuela.

Para Torres Fontes, los acuerdos de Torrellas-Elche (1304/1305) por los que se puso fin a la guerra y el reparto del reino de Murcia, supusieron la fragmentación de una región natural, como era la vega baja del río Segura, mediante el establecimiento

\footnotetext{
${ }^{35}$ Para la evolución de la guerra, Ferrer i Mallol muestra un detallado estudio de los acontecimientos vividos. Maria Teresa FERRER I MALLOL, Entre la paz y la guerra. La corona catalano-aragonesa y Castilla en la Baja Edad Media, Barcelona, 2005. Una buena recopilación y edición de fuentes a cerca de la conquista y gestión del territorio del reino murciano bajo dominación aragonesa la llevó a cabo Juan Manuel Del EsTAL GuTIÉRREZ, El Reino de Murcia bajo Aragón (1296-1305): colección de documentos del medievo alicantino, corpus documental, Alicante, 1999.

${ }^{36}$ Para Torres Fontes, "la historia medieval del reino de Murcia es la historia de una inseguridad". J. TORRES FONTES, El concepto concejil murciano de limosna en el siglo XV, en Actas $1^{a}$ Jornadas luso-espanholas de Historia Medieval, Lisboa, 1973, p. 839.
} 
de una frontera artificial y sin sentido. Desde el acuerdo de Torrellas-Elche la división de los reinos se convierte en un elemento regulador entre las dos comunidades para el paso de mercancías y personas, generando unas nuevas condiciones y secuelas en las comarcas que configuraron la nueva frontera ${ }^{37}$. A lo largo del reinado de Jaime II y sus sucesores se impuso en determinados momentos la prohibición tanto de salida de vecinos de la región recién conquistada como la entrada de murcianos o sus mercancías $^{38}$. Decisión del todo insostenible para cualquier región fronteriza, tanto en la actualidad como en la Edad Media, donde las conexiones comerciales y familiares estaban establecidas, pero que no dejan de ser significativas en lo tocante a la creación de una división, no solo administrativa, sino también de identidad. Para hacer efectiva la señoría de las tierras nuevamente conquistadas, los monarcas no sólo apelaron al elemento demográfico (expulsión de castellanos de la región, sin ninguna efectividad real $^{39}$ ), sino que paralelamente se llevó a cabo un proceso de "valencianización" a través de la imposición de unas instituciones nuevas como señala Ferrer i Mallol (fuero de Valencia, la procuración y la bailía como modelos organizativos espaciales...) que terminó por involucrar la región en la órbita de la Corona aragonesa. Sin embargo, la rápida incorporación de buena parte del reino murciano a Valencia dio como resultado un espacio desorganizado. No había una cabeza visible ni se trataba de un espacio histórico, pues hasta ese momento Murcia había sido la capital incontestable de la región ${ }^{40}$. En 1308 Orihuela consiguió que la nueva región anexionada tuviese un nombre propio, Procuración de Orihuela, y una demarcación administrativa particular, si bien el régimen jurídico que se aplicó fue general al reino valenciano, por mucho que Orihuela pretendiese que se mantuviera el fuero de Murcia (que ellos pedían que se llamase de Orihuela).

A pesar de que en 1305 el espacio se vinculaba al reino de Valencia, Jaime II mantuvo el antiguo límite fronterizo fijado en Almizra con valor militar y administrativo dentro del propio reino, para diferenciar las nuevas tierras de los límites tradicionales. Las tierras valencianas y las tierras recientemente anexionadas tenían solo en común el nombre, los fueros, la moneda y las cortes, ya que cincuenta años en territorio castellano habían facilitado la creación de condiciones diferentes a las habidas en

${ }^{37}$ Para ver un análisis pormenorizado de la sentencia de Torrellas/Elche y las consecuencias del mismo pueden consultarse los trabajos presentados al XVIII Congreso de Historia de la Corona de Aragón, que contó con una sesión específica sobre tal sentencia. Rafael NARBONA VIZCAÍNO (coord.), La Mediterrània de la Corona d'Aragó, segles XIII-XVI y VII centenari de la sentència arbitral de Torrellas, 1304-2004, Valencia, 2004.

${ }^{38}$ Los continuos problemas derivados por la política entre las dos cancillerías (aragonesa y castellana), así como los problemas derivados por la vida diaria en la región tenían su correlato en la apertura o cierre de las fronteras, claro exponente de la limitación del libre movimiento de las personas por los reinos cristianos como símbolo de castigo. En 1316 Jaime II obligaba a los vecinos de la procuración de Orihuela a no mantener tratos con los del reino de Murcia para presionar al concejo de la capital para aceptar a su yerno don Juan Manuel como adelantado del reino. En 1319 el cierre se producía por el destrozo de infraestructuras hidráulicas y se mantuvo hasta el año de 1322. Durante la guerra de 1356 a 1366 los monarcas de ambos reinos se dedicaron mutuamente a la expropiación de las tierras de los vecinos para otorgárselas a los naturales de los reinos dependiendo del momento de la ocupación. M.T. FERRER I MALLOL, Entre la paz y la guerra, pp. 315-320 y 459-461.

${ }^{39}$ En 1300, durante la ocupación de buena parte del reino de Murcia, Jaime II ordenó la expulsión de los castellanos que residían en él. Esta medida volvería a repetirse durante la guerra de los dos Pedros, decretando la expulsión de todos los vecinos castellanos en tierras aragonesas. Ibidem, pp. 72-73.

${ }^{40}$ J. V. CABEZUELO, Jaime II y la nueva articulación política del reino de Valencia (1291-1308), en Los cimientos del Estado en la Edad Media. Cancillerías, notariado y privilegios reales en la construcción del estado en la Edad Media (J.A. BARRIO, coord.), Alcoi, 2004, pp. 190-191. 
la corona aragonesa ${ }^{41}$. El hecho de compartir una misma lengua y un alto número de colonos asentados en las tierras provenientes de la Corona de Aragón habían facilitado el proceso de anexión ${ }^{42}$, pero no era suficiente para un proceso de homogeneización. $\mathrm{Ni}$ la lengua, ni el mismo sustrato cultural de los colonos fueron suficientes para identificar las tierras con el resto de los territorios de Jaime. Aunque el fuero impuesto de Valencia marcaba unas nuevas pautas de organización social, las villas mantenían los antiguos privilegios concedidos por los reyes castellanos, lo que las mantenía diferentes a las resto del reino valenciano. Todavía a mediados del siglo XIV, cincuenta años después de la anexión, Pedro IV se refería a estas tierras como las pertenecientes al reino de Murcia $^{43}$, a pesar de estar ya plenamente integradas en el régimen jurídico valenciano. Ello no quiere decir que estas gentes se sintiesen proclives a la unión con el antiguo reino de Murcia. En 1366 la guerra entre Castilla y Aragón daba un vuelco total, y todas las conquistas efectuadas por Pedro I de Castilla en tierras alicantinas (toda la procuración de Orihuela) eran recuperadas de nuevo por Pedro IV de Aragón, a quien se le presentó la oportunidad, además, de ocupar el resto del reino de Murcia en manos castellanas. Ante esta tesitura, los vecinos de la procuración consiguieron que el rey aragonés prometiera que no anexionaría las tierras de Orihuela a Murcia (en el caso de que el reino de Murcia entrase a formar parte de la Corona de Aragón), pero tampoco diluirse dentro de la gobernación de Valencia. Formaban parte del reino valenciano, pero con identidad propia ${ }^{44}$. Qué motivos tenían los vecinos de la procuración para no querer su adhesión al reino de Murcia. Sin duda alguna, la lengua y el tener unos orígenes naturales en la corona de Aragón ayudaban ${ }^{45}$. Sin embargo, estos elementos no son suficientes para querer su incorporación total al reino de Valencia, mas debieron jugar un papel importante para marcar sus diferencias frente a Castilla. Por otro lado, la creación de una frontera y la guerra mantenida entre los reinos originaba un sentimiento de movilización entre las comunidades, ahora enfrentadas, y obligaba a la necesidad de defender unos intereses vitales amenazados por la violencia. A través de estos elementos, se descubrían nuevas afinidades, se vivían nuevas experiencias vitales que surgen como defensa a unos ataques, creando así nuevos refugios a los individuos ${ }^{46}$. Si bien no son paraísos de identidad, sí que permiten un

${ }^{41}$ M.T. FERRER I MALLOL, Organització i defensa d'un territori fronterer. La governació d'Oriola en el segle XIV, Barcelona, 1990, p. 6.

${ }^{42}$ Bernat de Sarriá, procurador de la gobernación de Orihuela, escribía a Jaime II que había ganado tan rápidamente el reino de Murcia "per rahon dels catalans", y le recomendaba la expulsión de los castellanos, ya que "pensets vos per quals guaanyàs la terra e que al món no à tan gran deute com naturalea". Ibidem, p. 7.

${ }^{43}$ Ibidem, p. 5.

${ }^{44}$ Por un testimonio de 1407, un miembro del concejo de Orihuela pedía la supresión de una vieja costumbre castellana en la localidad puesto que dicha costumbre no se usaba en el reino de Valencia y era obligado que todas las tierras de la procuración "s'havien de regular segons el costum del regne on vivien". Está claro que no querían ser parte del reino de Murcia, sino continuar en Valencia. Ibidem, p. 8.

${ }^{45}$ Luis Rubio García, La Corona de Aragón en la Reconquista de Murcia, Murcia, 1989. Rubio García estimaba que en la repoblación de la ciudad de Murcia un 50\% eran catalanes, un $17 \%$ aragoneses y un $13 \%$ castellanos. Por lo que se refiere a Orihuela, según el estudio de Torres Fontes y Veas (J. TORRES FONTES y Francisco A. VEAS, La procedencia de los repobladores en el repartimiento de Orihuela, "MMM", XIII (1986), pp. 13-27) el 24'5\% de los repobladores eran catalanes, el 4'4\% neovalencianos, el 21'8\% castellanos, el 17'6\% aragoneses y el 6'4\% navarros. Y según Torres Fontes (J. TORRES FONTES, Repartimiento de Lorca, Murcia, 1977) en la repoblación de Lorca la participación catalana osciló entre el 14'01\% del primer repartimiento (1266) y el 20'68 del cuarto (1330-1337), y la de los neovalencianos entre el 1'86 del primer repartimiento y el 8'03\% del cuarto.

${ }^{46}$ Manuel CASTELls, El poder de la Identidad, Madrid, 1998. 
cierto grado de definición ya que la homología es un elemento tan importante como los elementos de diferenciación en los procesos de identidad ${ }^{47}$. Es decir, Los enfrentamientos mantenidos por las Coronas castellanas y aragonesas facilitaron que dichos espacios tomasen posición por sus respectivos reinos, ante la amenaza a la que se veían sometidas las tierras. De esta manera, se reforzaron los lazos de cohesión y adscripción y provocaron, como se puede ver en la procuración de Orihuela, la total diferenciación respecto al resto del reino de Murcia en manos castellanas. Se van a convertir en defensores del reino valenciano frente a un enemigo exterior, desarrollando de este modo un sentimiento pro valenciano acusado, si bien ello no va a ser óbice para marcar claramente las diferencias dentro del reino de Valencia al mismo tiempo. Como veremos a continuación, la guerra en la frontera no puede considerarse como meros enfrentamientos por una división administrativa dentro de los reinos cristianos, sino causantes de la diferenciación de las respectivas comunidades.

Los esfuerzos institucionales (ferias, mercados, privilegios fiscales...) no consiguieron, a pesar de su propósito, el poblamiento en el reino de Murcia y en la Procuración de Orihuela. La cuestión es sencilla si comprobamos las dificultades y peligros que la presencia de la frontera imponía. Una descripción rápida de la situación de las villas en estos siglos XIV y XV nos desvela la reducción de la población y su concentración en villas y ciudades amuralladas. Así mismo, se aprecia una disminución considerable de mudéjares que preferían emigrar a Granada antes que trabajar en condiciones de semiesclavitud ${ }^{48}$, ligeramente mitigada en las encomiendas de la Orden de Santiago ${ }^{49}$. Se produjo una mayor diferenciación social impuesta por las funciones militares y las características ganaderas de la región, así como la formación, distinción y crecimiento de cofradías artesanales, manifestación de la ausencia de un carácter eminentemente agrario. Por otra parte, los campos deshabitados impulsaron la expansión ganadera, especialmente en el lado murciano, lo que facilitaba las penetraciones de almogávares granadinos ${ }^{50}$. En el Libro de la Caza de don Juan Manuel podemos apreciar la expansión de los despoblados que facilitaban la existencia de tierras incultas a lo largo y ancho del reino de Murcia, desde la frontera de Granada a la de Valencia. En la Guerra de los dos Pedros, el infante Ramón Berenguer, tío del Ceremonioso y encargado de la defensa del reino de Valencia, informaba al rey de la lamentable situación del reino en su parte meridional (Procuración de Orihuela) lo que no aconsejaba iniciar ataques a Castilla por ese sector, ya que los ejércitos no se podrían abastecer, y la única manera de plantear la guerra por dicha región era a través de una postura defensiva ${ }^{51}$.

Los motivos para la situación de escasez demográficas son obvios. El reino de Murcia mantenía una frontera con Granada en la que durante doscientos años (1266 hasta 1486) apenas existieron variaciones a excepción de las conquistas de pe-

\footnotetext{
${ }^{47}$ J. CARo BAROJA, Razas, pueblos, pp. 265-268.

${ }^{48}$ Un testimonio coetáneo a la guerra de 1296-1304 recoge que "por razon de las guerras e de los otros males que son acaecidos en tierras de Murcia, la mayor parte de los moros son muertos e los otros fuydos, por las quales cosas la tierra es muy despoblada e menguada dellos". El ataque hacia las comunidades musulmanas en tiempos de violencia fue muy recurrente, además de por el posible odio existente fruto de la ideología de cruzada, por el valor ecónomico que alcanzaban al considerarse como mano de obra para las tareas agrícolas en señoríos y otras propiedades. J. TORRES FONTES, Los mudéjares murcianos en el siglo XIII, "Murgetana”, XVII (1961), pp. 57-90.

${ }^{49}$ Sobre el comportamiento de las encomiendas santiaguistas en el reino de Murcia, y el trato hacia los mudéjares, consúltese M. RODRÍGUEZ LLOPIS, Señorío y Feudalismo en el reino de Murcia, Murcia, 1985.

${ }^{50}$ J. TORRES FONTES, La frontera murciano-granadina, Murcia, 2005, p. 19.

${ }^{51}$ M.T. FERRER I MALLOL, Entre la paz y la guerra, pp. 361-362.
} 
queñas fortalezas que se recuperan pasado breve tiempo. En realidad, la presencia de la frontera originaba correrías, incursiones fugaces pero devastadoras para las gentes que vivían en el reino. La tónica general durante estos dos siglos fue la sucesión de cortos periodos bélicos delimitados por largas treguas ${ }^{52}$. Pero esas treguas no eliminaban la inseguridad, pues desde que en 1266 los meriníes hicieron acto de presencia en territorio granadino, y la posterior consolidación del emirato de Granada forzó la despoblación de las comarcas vecinas. La actividad de los granadinos, caracterizada por su movilidad, frecuencia y profundidad de sus penetraciones no supuso conquistas territoriales pero sí su dominio de la frontera y el facilitarles sus incursiones que llegaron hasta las proximidades de la capital, y aún se adentraron en tierras oriolanas y manchegas. Estas cabalgadas eran todo rapidez; se asaltaba, se incendiaba, se talaba, se robaba y cautivaba. En las comarcas vecinas a la frontera la acción depredatoria era más intensa porque no sólo se quemaban cultivos, especialmente cereales, sino que la tala de arbolado, viñedos, destrucción de obras de riego o puentes y casonas fortificadas se realizaba de manera sistemática para que sus habitantes tardasen en rehacerse. Por ello, los vecinos se decidían a alejarse y abandonar el territorio, ya que el coste de rehacer todos los desperfectos ocasionados por las incursiones era demasiado para modestos agricultores. El vacío demográfico se hizo cada vez más intenso lo que ocasionó que las penetraciones granadinas tuviesen que ser más profundas porque nada se encontraba cerca de la frontera ${ }^{53}$. Si todos estos factores ayudaban a la creación de una psicosis hacia la frontera, en cuanto a la identificación de la presencia del otro (en este caso del elemento granadino), la frontera murciano/valenciana terminó por convertir la región en un espacio verdaderamente hostil.

Desde finales del siglo XIII la guerra entre Castilla y la Corona de Aragón tiene en estas tierras una labor devastadora. La guerra se presenta de manera intermitente, pero continua. No puede, por tanto, obviarse el factor de la guerra como elemento condicionante en el panorama murciano y alicantino. En la década de 1360 localidades como Orihuela o Alicante tenían problemas para defender las murallas ante la ausencia de vecinos. Edictos de los concejos impedían la emigración hacia tierras del interior del reino de Valencia, lo que demuestra lo que tal acción conseguía ${ }^{54}$. La huida de gente hacia tierras más seguras tiene una explicación muy clara a tenor de las órdenes que el rey Pedro I de Castilla daba al concejo de Murcia:

E quando el dicho don Enrique Enriquez [adelantado mayor de la frontera y caudillo del obispado de Jaén] e el dicho don Farag [noble granadino] quisieren ir a talar a Orihuela o a fazer otras cosas algunas que son mio seruiçio, yd con ellos a fazer todas las cosas que vos dixeren que son mio seruiçio, e talad muy bien Orihuela que non finque cosa de ella por talar, e fazer la mas cruel guerra que pudieredes e quantos omes tomaredes, cortadles las cabezas, que non finque ome de Aragon que sea tomado que non sea luego muerto ${ }^{55}$

El fin de la guerra en 1369 no significó el fin de las hostilidades. En 14291430, de nuevo el conflicto entre Castilla y la Corona de Aragón provocó que Yecla,

52 J. TORRES FOnTES, La frontera murciano-granadina, Murcia, 2004, pp. 12-13.

${ }^{53}$ Ibidem, p. 24.

${ }^{54}$ M.T. FERRER I MALLOL, Entre la paz y la guerra, p. 396.

${ }^{55}$ AMM, Actas Capitulares, 1364-1365, ff. 56v-56r., Publicado por Ángel Luis Molina MolinA, Murcia en el siglo XIV. Aportaciones para su estudio, Murcia, 1999, pp. 109-110. Dicha carta está lejos de ser mera retórica, ya que el el rey amenazaba a los vecinos de Murcia con la decapitación de todos aquellos vecinos de Murcia que no se afanasen en la guerra cruel contra el reino de Valencia. 
Villena, Caudete o Hellín fuesen saqueadas e incendiado parte del caserío, al tiempo que las tropas murcianas corrían una y otra vez las tierras de la procuración de Orihuela ${ }^{56}$. Al hecho de la guerra y sus asedios, se unió la labor de depredación de los almogávares que terminó por condicionar la concentración en habitas urbanos. A lo largo de toda la frontera los almogávares, gentes que vivían de la frontera, se dedicaban al robo de ganado y de mudéjares. Gente eficaz para la guerra por su conocimiento del territorio, en períodos de paz hacían del conocimiento de la región un arma eficaz para ganarse la vida a través del pillaje y la extorsión. Almogávares murcianos atacaban tierras alicantinas, mientras que los de Valencia hacían lo propio con las murcianas. Cabezuelo Pliego nos demuestra la organización que dichas bandas poseían, con numerosos colaboradores para la ocultación del botín y su posterior traslado a otras partes de los reinos ${ }^{57}$. Su perfecta articulación los convertía en verdaderos malhechores que atemorizaban a las comunidades cercanas a la frontera, sobre todo agricultores y pastores que tenían que dejar atrás la seguridad de los muros de la ciudad, ya que su rápida actuación, sigilo y contundencia contaban con la ventaja del refugio en el reino vecino.

Si bien este hecho puede ser considerado como una muestra de violencia más en el ámbito cristiano, aquí juega otro elemento básico como es la jurisdicción independiente. Al problema de la violencia y robo de ganado se suma la imposibilidad de actuar libremente contra los malhechores, remarcando un valor más de defensa contra un vecino del que hay que cuidarse, y al que se le crea una fama por la diferenciación clara del elemento jurisdiccional y la protección que ello otorga. Las relaciones entre los reinos cristianos se muestran muy complejas, puesto que las interconexiones familiares entre las propias dinastías reinantes, las dependencias comerciales, el sentimiento de cruzada contra el Islam, etc. hacían que se pasase de la guerra a la alianza con una facilidad pasmosa. Sin embargo, no se dudaba en recurrir a los derechos de soberanía de cada monarca sobre sus súbditos cada vez que lo consideraban necesario. Después de la invasión del reino de Murcia, el rey aragonés Jaime II se mostró colaborador con don Juan Manuel y el infante don Pedro en la minoría de Alfonso XI buscando el consenso y apoyo entre los dos nobles, máximas figuras de la política castellana del momento, y ambos yernos del rey aragonés. La estrecha vinculación de Jaime II con don Juan Manuel a quien apoyó enormemente, sin embargo, tenía una limitación. La intervención de vecinos de Orihuela para ayudar a la ciudad de Murcia en su oposición contra don Juan Manuel para ser reconocido como adelantado del reino de Murcia ${ }^{58}$ llevó a éste a reclamar a su suegro la extradición de tales vecinos para ser castigados por los disturbios generados, una vez que pudo controlar la situación y apropiarse de la ciudad ${ }^{59}$. No obstante, el rey, a pesar de lamentar los sucesos, pues había muerto uno de los hombres de don Juan Manuel, se negó a extraditar a vecinos de Orihuela a Murcia alegando que no estaba prevista por los pactos

${ }^{56}$ M. RodríGueZ Llopis, Historia de la Región de Murcia, p. 150.

57 J.V. CABEZUELO, El negocio del rapto en la frontera de Orihuela a principios del siglo XIV, "MMM", XXI-XXII (1997-1998), pp. 43-58.

${ }^{58} \mathrm{El}$ adelantamiento era una institución que usó la monarquía en ciertas regiones para el control del territorio. Desde 1258 el reino de Murcia contó con un adelantado que impartía justicia en nombre del rey, dirigía la defensa de la frontera, y hacía cumplir las ordenanzas del rey.

${ }^{59}$ Don Juan Manuel, señor de Villena, ostentaba también el título de Adelantado del reino de Murcia. Si bien su política en el señorío de Villena se muestra muy condescendiente hacia sus pobladores en aras de reactivar la región, su actuación en Murcia se mostró abusiva y tendente a obtener los mayores recursos que pudiera. J. TORRES FONTES, Problemática Murcia-don Juan Manuel durante la minoría de Alfonso XI, "Anales de la Universidad de Alicante, Historia Medieval", 11 (1997), pp. 315-331. 
entre la Corona de Aragón y Castilla, y por tanto, cada uno de los reyes tenía señoría sólo sobre sus propios reinos ${ }^{60}$. Por otro lado, al igual que ocurriera con la frontera granadina, era necesario el establecimiento de instituciones como los alfaqueques o trajumanes para la redención de los cautivos generados durante las guerras. Esta necesidad de reconocer instituciones arbitradoras para la solución de los conflictos de los cautivos demuestra la visión de espacios diferentes en los que se debía regular estrechamente el modo de gestión de las consecuencias de la violencia generada en la frontera. No se podía circular libremente por los reinos buscando la redención de los familiares, sino que debía ser a través de una regulación muy específica y estricta la que permitía la presencia de los extranjeros en caso de guerra ${ }^{61}$. Aunque en tiempos de paz las justicias de los respectivos reinos se podían mover con mucha mayor libertad buscando la persecución de los malhechores, no obstante, las quejas frecuentes de los concejos y de los monarcas por la violencia (robos, muertes ${ }^{62} \ldots$..) traslucen la necesidad de acuerdos para la intervención. Y en último caso, cuando se recurre a los monarcas, el reconocimiento implícito de la pertenencia a identidades totalmente diferentes.

\section{LOS CONFLICTOS CENTRO-PERIFERIA}

Se ha comprobado en las páginas anteriores cómo unas condiciones determinadas pueden provocar nuevos sentimientos de identidad. La Península Ibérica presenta un panorama en la Edad Media de acusadas diferencias entre las regiones. Las propias fuentes hacen mención a componentes étnicos (lengua, naturales de una determinada región...) que se muestran totalmente cristalizados a finales del siglo $\mathrm{XV}$, y que han generado a lo largo de los siglos precedentes numerosos conflictos por la defensa de un territorio y sus instituciones. En este contexto, las fronteras simbolizan algo más que una mera división administrativa de la España Medieval. Sin embargo, se produjo la unión de buena parte de los reinos peninsulares bajo una misma corona, y con una ideología subyacente como era la reconquista. ¿Cómo respondieron las comunidades ante dicho acontecimiento? ¿Se produjeron actos de defensa frente a la posible pérdida de identidad diluida tras la formación de una unidad mayor? ¿Se trataba de un proceso de centralización frente a la defensa de las identidades de las periferias? Ya hemos observado como a pesar de las políticas de la corte existe una identidad de los grupos que juega un papel muy importante en la aceptación, y a la vez contestación, de dichas ideas uniformadoras. El análisis del desarrollo de una sociedad centralizada frente a la oposición de las periferias no resulta

\footnotetext{
${ }^{60}$ M.T. FERRER I MALLOL, Entre la paz y la guerra, p. 322.

${ }^{61}$ En el acuerdo establecido entre el adelantado de Murcia y la ciudad de Orihuela en febrero de 1430 para el rescate de cautivos, se acordó que los encargados de tales negociaciones serían dos alfaqueques, uno por cada bando y previa aceptación de los mismos por las partes. Además, se establece el número de bestias que podrían acarrear para su negocio, así como un único acompañante. AMM, Cartas Antiguas y Manuscritos, leg. 785, doc. 7, s.f.

${ }^{62}$ El robo de ganados, el cautiverio, la petición de rescate, etc., cuentan con numerosos testimonios en los archivos y ha sido muy estudiado por los historiadores del reino valenciano. Todo el siglo XIV cuenta con ejemplos de los saqueos de ganado, represalias por parte de las autoridades que se materializaba en el robo, a su vez, de ganados y bienes de los naturales del otro reino. J.V. CABEZuelo, El negocio del rapto en la frontera de Orihuela; José Hinojosa Montalvo, Las fronteras del reino de Valencia en tiempos de Jaime II, "Anales de la Universidad de Alicante. Historia Medieval", 11 (1996-1997), pp. 213-228. El principal motivo de los secuestros se realizaba en mudéjares por su fácil venta en otros mercados (Ordenes militares en Castilla, ámbitos agrarios dónde trabajaban en condiciones de semiesclavitud, norte de África...).
} 
válido. La idea de pertenencia a una misma nación se utiliza en igual medida que las identidades de grupo o singulares por parte de los individuos, es decir, en constante paradoja. La necesidad de los individuos, de las instituciones, de los grupos o de las comunidades de perpetuarse llevará a la defensa de la identidad en función de los fines buscados por quienes formulan dicha adscripción. A lo largo de las siguientes páginas observaremos cómo la monarquía entendió la unión y qué valor representaba para ella la defensa de una situación preexistente y sus fronteras, a pesar de los mensajes que podemos ver en las crónicas de la unión por fin de España.

Durante los siglos bajomedievales, tanto Castilla como Aragón se habían constituido como dos espacios definidos, con unas identidades claras y diferenciadas que traducían un modo de vida en la frontera propio de cualquier relación entre reinos distintos. La unión de buena parte del territorio peninsular bajo el reinado de los Reyes Católicos a finales del siglo XV no podía sino reflejar las realidades de varios reinos que se unían bajo una monarquía, pero que hacía muy difícil una asimilación total o identificación con un proyecto único o "nacional". Es por ello que la frontera siguió manteniendo cierta vigencia al respetarse el significado y la presencia de las mismas tras la unión de 1479. Si bien el elemento conflictivo desaparecerá, no ocurrirá lo mismo con el valor de las identidades. La razón se debe, en cierta manera, al proceso de unión de los reinos. Aunque algo posterior al período aquí analizado, Peter Sahlins demuestra cómo Luis XIV puso gran interés en la asimilación lingüística y pedagógica de las elites locales de los nuevos territorios que ganaba para Francia. Además, tras la conquista de los mismos, estos pasaban automáticamente a ser provincias y territorios con iguales derechos que el resto de los súbditos del monarca ${ }^{63}$. Por el contrario, no existía un concepto de "nacionalidad" española durante el periodo de los Reyes Católicos, sino un compendio de nacionalidades que componían esa Monarquía Hispánica. Se trataba de vasallos o súbditos de los reyes de España, que técnicamente eran condes de Barcelona, reyes de Castilla, reyes de las dos Sicilias, etc ${ }^{64}$. Isabel y Fernando habían conseguido engrandecer sus títulos con la suma de nuevos de patrimonios $^{65}$, pero la naturalidad de cada una de las regiones seguía contando, y no sólo en un plano mental de identificación, sino también en materia económica y jurídica. Cada región seguía comportándose de manera particular en lugar de buscar intereses generales. Castilla, por ejemplo, vedaba el acceso a las instituciones a los naturales de otros reinos ${ }^{66}$, y el comercio con América era sólo responsabilidad de castellanos. En este contexto, la frontera seguía teniendo algún valor como el de antaño ante la

${ }^{63}$ P. SAHLINS, Boundaries: The making, p. 117

${ }^{64}$ Ibidem, pp. 113-114.

${ }^{65}$ Los monarcas consideraban la herencia de los reinos que constituían la monarquía hispánica como partes constituyentes de un mayorzago. Ello puede implicar necesariamente ir en contra de la lógica de unos intereses nacionales que en nada tendrían que ver con las campañas y esfuerzos desarrollados en el extranjero. Domínguez Ortiz, en relación a la política de Carlos V muestra a las claras esa ausencia de vinculación "nacional" de los monarcas con el territorio español. La división de la herencia de Carlos V parecía ofrecer a Felipe II una oportunidad de liberarse de pesadas hipotecas, de aliviar a los españoles y a España del fardo pesadísimo de la política imperial. La oportunidad fue desechada o, por mejor decir, no fue tenida en cuenta, porque ni Felipe II ni sus sucesores se consideraron meramente reyes de España y obligados a seguir una línea política acorde con los intereses de este país. España estaba subordinada a una política de más altos vuelos que tenía como objetivos mantener la integridad de los dominios de la Casa de Austria, considerada como una especie de mayorazgo indivisible e inalterable. Antonio DomínguEZ OrTiZ, España, Tres milenios de Historia, Madrid, 2001, p. 140.

${ }^{66}$ Cortes de los Antiguos Reinos de León y de Castilla, Real Academia de la Historia, Madrid, 1882, tomo IV, Cortes 1523, petición 30, p. 374. 
falta de voluntad por parte de la monarquía de realizar cambios en la articulación del espacio $^{67}$. La existencia de la frontera seguía manteniendo la diferencia jurisdiccional, creando un vacío legal que hizo que el contrabando y la violencia no se erradicara por completo, como aún se demuestra en 1601 en el testimonio sobre las posadas situadas en las proximidades de la frontera con Valencia en Requena:

\begin{abstract}
Si saben que la casa venta que los dichos Pedro Sanchez Monsalve y su muger fundaron que posee el dicho mossen Jayme Colomina sobre que es este pleito esta sita y fundada junto de la rraya y mojon que dibide este reyno de Castilla y el de Valencia, de tal manera que dende la dicha venta se puede con una piedra llegar a la dicha rraya y mojón por lo qual la dicha venta esa hecha y fundada alli en muncho deserviçio del rey nuestro señor porque los honbres forajidos y de mala vida que ubiere y ay en el dicho reyno de valencia e se pasan y ponen alli para sigurar sus personas de las justicias de aquel reino y toman mantenimientos, y lo mismo haçen y pueden haçer los de este reyno de Castilla pues estando alli con fazilidad estan en el / un reyno y en el otro para remedio de lo qual conviene al servicio de su magestad se quite y derrive de alli como cosa tan en deservicio suyo ${ }^{68}$.
\end{abstract}

Carlos I, en cartas a los "lugares de la frontera" de la Corona de Castilla, hace mención a los "reynos estranos comarcanos" refiriéndose a las otras regiones españolas no incluidas bajo dicha Corona ${ }^{69}$. Todavía en 1523 parece que quedaba mucho camino para olvidar las "fronteras menores" de la Península Ibérica. De sobra es conocida la pervivencia de las estructuras jurisdiccionales de cada Corona tras la unión de los Reyes Católicos (necesidad de convocar cortes en cada uno de los reinos para la consecución de subsidios y aprobación de normas, diferencia judicial, de lengua, institucional, incluso de moneda en cada uno de los reinos, etc.), por lo que no haremos más redundancia en ello, a fin de centrarnos en otros de los aspectos importantes del ámbito fronterizo, como fue el régimen aduanero. A diferencia de otros impuestos de tránsito como pudieran ser los portazgos, pontazgos, servicio y montazgo, etc, las aduanas no eran simplemente lugares para el pago de una tasa, sino que su existencia posibilitaba la regulación de las relaciones comerciales y personales entre los diferentes reinos. Si a partir de la unión no se dictaron expulsiones de súbditos como las ocurridas en el siglo XIV, no podemos decir lo mismo de las mercancías. La política aduanera simbolizaba la facultad de la monarquía de poder definir un espacio económico coherente que aportaba elementos de definición a dicho reino ${ }^{70}$.

${ }^{67}$ En el testamento de Isabel I (12 de octubre de 1504), Castilla y todas sus propiedades pasaban a su hija Juana, siendo administrador general del reino Fernando siempre que los reyes (Juana I y Felipe I) no estuvieran o no pudieran hacerse cargo de la gobernación (disposiciones 23 a 27 del testamento). Isabel se refiere a sus reinos, tierras y señoríos, independientes de las tierras de la Corona de Aragón. Antonio DE LA ToRre, Testamentaria de Isabel la Católica, Madrid, 1974. Por su parte, Fernando en su testamento (22 enero de 1516) también hizo donación a Juana del reino de Navarra (cláusula 31). Este tipo de donaciones no hacen sino remarcar la fuerte identidad de cada uno de los reinos, que son recibidos en herencia por los monarcas hispanos como partes indivisibles de un mayorazgo, más que como una realidad nacional a conservar entendida como España.

${ }^{68}$ Archivo de la Real Chancillería de Granada leg. 5413, pieza 7, ff. 105-106v.

${ }^{69}$ AGS, Consejo Real, leg. 91, exp. 5, s.f. Carta dirigida a los alcaldes de sacas en 1523, especialmente en los obispados de Cartagena, Cuenca y Osma, para que luchen contra el paso de mercancías vedadas de Castilla a Aragón. Sin foliar.

${ }^{70}$ En la Edad Media los monarcas lo desarrollaron a través del fomento del comercio y su fiscalización, es decir, ferias, impuestos de base indirecta, privilegios, etc. David IGUAL LuIS, Política y 
José María Sánchez argumenta que se puede hablar de una economía mercantilista en Castilla en la Baja Edad Media por la que el poder político conseguía engrandecer a la propia monarquía por medio del sometimiento de la economía a los designios de la Corona a través de la prohibición (control) de los intercambios. El mercantilismo promocionaba el comercio como base de la riqueza de las naciones y el control de su flujo era una necesidad imperante. Por lo tanto, la regulación de los intercambios comerciales entre Aragón y Castilla tras la unión, así como la prohibición de ciertas mercancías, estaría denotando la continuación de políticas particulares propias de la época anterior a 1479, y la diferenciación de las diversas unidades constituyentes de la Monarquía como espacios independientes. Las fronteras, con sus aduanas, permanecieron inalterables, destacando tan sólo el reinado de los Reyes Católicos en el que existió un cierto relajo en contraposición a lo ocurrido tras su reinado.

Las Cortes de Toledo de 1480 recogían el acuerdo por el que se suprimían las cosas vedadas. A partir de ese momento toda persona podría mover libremente los productos que quisiera, pagando el acostumbrado diezmo, de tal manera que "los naturales dellos [de cada uno de los reinos] traten e comuniquen en sus tratos e fazimientos". Se transformaban así las aduanas en impuestos que gravaban el paso de mercancías, pero que no regulaban su flujo por medio de prohibiciones $^{71}$. Mas la libertad no fue total, y los reyes excluyeron de dicha ley la moneda. Este acuerdo tuvo una importante repercusión sobre la región fronteriza de Murcia, especialmente en la parte norte comprendida en la gobernación del Marquesado de Villena. Sin embargo, la ley de 1480 se vería modificada en numerosas ocasiones. Bajo el pretexto de hambres y carestías la frontera volvía a cobrar su significado, y se pedía la vuelta a las restricciones, como pedían los procuradores en 1506:

vysta la grand neçesydad que en estos rreynos ay de pan y ganados e otros mantenimientos, y el grand daño que de la saca dello se ha rreçebido e rreçibe, suplican a Vuestras Altezas que manden e defiendan, so grandes penas, que de aquí adelante no saquen ni lleven fuera des/tos rreynos pan ni ganados, ni mulas, ni cauallos, ni otros mantenimientos, ni las otras cosas vedadas, segund lo disponen las leyes destos rreynos, y manden executar las penas dello con mucha deligençia ${ }^{72}$.

economía durante la Baja Edad Media. El papel de la monarquía en el comercio exterior valenciano, en Los cimientos del Estado en la Edad Media, pp. 249-272. La Corona de Castilla tenía el impuesto llamado "de aduana" mientras que la Corona de Aragón creó el impuesto de la "quema". Ambos gravaban los productos que se dedicaban al comercio entre los reinos. Como afirma Diago Hernando, la importancia y existencia en Valencia de la quema resulta ya muy revelador de hasta qué punto cuando se decretaba la prohibición de la exportación de una mercancía no se aspiraba habitualmente a impedir de forma radical su salida, sino a lo sumo a someter a un mayor control su comercialización y de paso obtener ingresos adicionales a través de la venta de licencias de exportación. Máximo DiAgo HERNANDO, Introducción al estudio del comercio entre las Coronas de Aragón y Castilla durante el siglo XIV, "En la España Medieval”, 24 (2001), pp. 47-101. Para un mayor análisis del papel desempeñado por la monarquía aragonesa para obtener beneficios de la política aduanera, consúltese Máximo DIAGo HeRnANDO, La "quema": trayectoria histórica de un impuesto sobre los flujos comerciales de Castilla y Aragón (siglos XIV y XV), "Anuario de Estudios Medievales", 30/1 (2000), pp. 229-242.

${ }^{71}$ Ley 111 de las Cortes de Toledo de 1480. Cortes de los antiguos reinos de Leon y Castilla, Tomo IV, pp. 185-186.

${ }^{72}$ A la petición 14 realizada por los procuradores, la Corona respondió "Que se haga en quanto a lo del pan e cauallos, en quanto a lo ál, que lo mandará ver”. Ibidem, pp. 227. 
A lo largo de las primeras décadas del siglo XVI apreciamos como durante la vida de Fernando el Católico el empeño para el mantenimiento de la libre circulación fue un hecho, no ocurriendo así durante el gobierno de Felipe I o de Carlos I, quienes acudieron a la regulación de las mercancías para asegurarse el abastecimiento de las ciudades y la regulación de los $\operatorname{precios}^{73}$. Similares circunstancias se habían producido a lo largo del siglo XIV y XV en el que las diferentes leyes de Castilla abrían o cerraban las fronteras a la libre circulación, pero en la que primó siempre una política proteccionista que continuó tras los Reyes Católicos. El cierre de las fronteras de Castilla perjudicaba fundamentalmente a Valencia, pues la dependencia de este reino respecto a ganados y trigo era considerable. Destaca la labor de Enrique III de Castilla en la prohibición de exportaciones (e incluso importaciones) del reino vecino mientras que Martín I de Aragón le pedía encarecidamente la consideración de tales posturas. La argumentación del rey aragonés consistía en que cada rey tenía el derecho, y podía, buscar su bien particular. Pero, continuaba el monarca, las "inhibiciones" no debían durar más que el tiempo necesario para paliar las circunstancias adversas que habían aconsejado el cierre de las fronteras, debiendo volverse inmediatamente después a la libre concurrencia de mercancías y personas ${ }^{74}$. Fernando el Católico, consciente de las circunstancias del reino valenciano puso un gran empeño en la defensa del privilegio de la unión, como se demuestra en las cortes de 1512. En dichas cortes, los procuradores castellanos pedían la reversión de la situación de las aduanas a un punto anterior a la unión:

Otrosi suplicamos a vuestra Alteza que porque de la saca de las carnes y co-
lanbre que destos rreynos en el hazen se siguen tantos y tan grandes damp-
nos como a vuestra Alteza es notorio, lo mande rremediar, porque según
puja la carne, si no se rremedia, espérase que se comerá la carne a tan altos
preçios que no se pueda sufrir, y estos rreynos reciben mucho dampno.

El monarca hizo valer las tesis de las cortes de 1480, tal vez consciente de la necesidad que sus tierras de Aragón, especialmente Valencia, tenían de los productos castellanos:

Que por las Cortes de Toledo se hizo esta ley aviendo consideración a la hunion y hermandad que estos rreynos tienen con Aragon, y que reuocarse no se podria hazer sin cavsar algun escandalo, y que en lo de los colanbres que ellos pueden hazer hordenanças en sus pueblos, y hechas las enbien al Consejo ${ }^{75}$.

Los problemas sobre cierre de fronteras, impedimento a la libertad de comercio a través de impuestos y permisos especiales son constantes a lo largo de los siglos XIV y XV, levantando las protestas de los pueblos fronterizos que vinculaban su economía a la relación con los reinos vecinos. Estas protestas no revelan sólo el descontento por el cierre de las fronteras llevadas a cabo por los reinos contrarios, sino también por las medidas adoptas por sus propios monarcas que impedían el comercio. Si bien los reyes tomaban estas medidas como represalia contra el monarca vecino (guerra, conflictos aislados entre los reinos, etc.) en un acto de reafirmación de identidad, ello no era óbice para que surgiesen las protestas y quejas por parte de

\footnotetext{
${ }^{73}$ Cortes de 1523, petición 40, Ibidem, p. 377; peticiones 69 y 70, Ibidem, p. 385.

${ }^{74}$ M.T. FERRER I MALLOL, Entre la paz y la guerra, p. 527.

${ }^{75}$ Cortes de los Antiguos reinos de León y de Castilla, Tomo IV, Cortes de 1512, pp. 241-242.
} 
las comunidades fronterizas ${ }^{76}$. Esta supuesta rivalidad centro/ periferia debería haber desaparecido tras el proceso de unión de las Coronas, tal y como en la declaración de intenciones de Isabel y Fernando se recoge en las cortes de Toledo de 1480. La consecución del ideal de la restauración de la monarquía visigoda, la finalización de un largo proyecto de unión de un mismo pueblo recogido en la corte de los Reyes Católicos debería haber colmado las ansias de las comunidades fronterizas de poder desarrollar su economía de ámbito regional sin problema. Sin embargo, nos enfrentamos ante el hecho de que fueron las comunidades fronterizas las más acérrimas defensoras de esa unidad frente a un centro, una corte, que parece utilizar el mensaje goticista para otros intereses muy alejados a los de la realidad cotidiana de los súbditos. Se produce la paradoja de la reivindicación por parte de los grupos periféricos de la unidad frente a la tradicional división de reinos mantenida por la Corona. Por eso, la permanencia de las restricciones debía generar, obligatoriamente, una economía de contrabando.

En 1530 el comercio ilegal era tan manifiesto y tan presente en las vidas de los vecinos como lo había sido durante toda la Edad Media. Las penas impuestas en Castilla a lo largo de la Edad Media indicaban la severidad y el valor que los monarcas otorgaban a la frontera y muestra el conflicto de proyectos divergentes ${ }^{77}$. Luis Juan Tárrega, alcaide de la fortaleza de Almansa, se erigió en uno de los portavoces de los vecinos de algunas localidades del reino de Murcia situadas en la frontera con Valencia, y lamentaba la actuación de un juez que con veinte hombres armados se dedicaba a imponer las penas y a cometer abuso con la intención de frenar las "sacas de pan" (envío de cereal al reino de Valencia). Según el alcaide, la mayoría de la población de la provincia vivía del acarreo de mercancías y de la venta de productos en el reino valenciano, y era muy posible que más de siete mil súbditos de la Corona se viesen abocados a la indigencia si continuaba la política de cierre de aduanas. Los concejos no tenían inconveniente en reconocer la contratación de pan, carne y otras mercancías con los reinos de Aragón y de Valencia. Los vecinos de los pueblos se quejaban de que el rey continuaba con la prohibición de sacar viandas y otros productos de Castilla a pesar de haberse producido la unión de ambas Coronas, lo cual causaba mucho perjuicio a la región, siendo la solución la revocación de las medidas prohibitivas:

por el dicho vedamiento se les siguen dichos muchos [sic] de penas y achaques y estorsiones y cohechos. Que se llieuan a los que se hallan culpados y transsgresores del dicho vedamiento y algunos dexan sus casas y se ausentan por temor de las dichas penas y proçesos criminales que se hazen en ellos por juezes de comision o ordinarios. Sobre lo qual, querellandose de los dichos agrauios y danyos particulares de los dichos pueblos y dando a entender que sea como es bien comun y vniuersal de los dichos reynos de Castilla la saca del pan y carne en respeto que por ella se acrecientan las lauores y la cria y tratos de los ganados y se enriquecen los dichos reynos y se augmentan con ellos las rentas reales y otros derechos, y que conforme a la vnyon de los dichos reynos sea justa la comunicacion de las dichas cosas vedadas y otras mercadurias con los dichos reynos de Aragon y Valençia por ser como son todos vnos y subditos de su Cesarea Magestad y para conseruacion de toda paz y concordia entre ellos y por otras justas causas ${ }^{78}$.

\footnotetext{
${ }^{76}$ M.T. FERRER I MALLOL, Entre la paz y la guerra, pp. 315-316, y pp. 528 y ss.

${ }^{77}$ Estas llegaban incluso hasta la condena a muerte a los que sacaran las mercancías. Ley de Juan I en las Cortes de Guadalajara de 1390. Recogida las Ordenanzas Reales de Castilla glosadas por Alfonso Díaz de Montalvo en la década de 1480. Libro VI, título IX, ley VIII.

${ }^{78}$ AGS, Diversos de Castilla, Memoriales, leg. 220, doc. 52, s.f.
} 
Los pueblos fronterizos del norte del reino de Murcia se dirigieron por carta al gobernador del Marquesado de Villena para que intercediese ante el rey, junto con un aval del procurador del reino de Valencia, Fernando de Aragón. Informaban al rey que Valencia se encontraba muy mal servida de cereales, y el deber del monarca era abastecerla, lo cual se conseguiría quitando el vedamiento. Las localidades de Villena, Almansa, Yecla y Sax afirmaban que para evitar la despoblación de los concejos, muchos de ellos habían tenido que llegar a igualas con las autoridades reales a la hora de pagar las multas para que no emigrase la gente:

e que todos los dichos daños se les syguen del dicho vedamiento e ni por el se dexan todavia de sacar el dicho pan et carnes por las personas que no puden vivir e sustentanse syn los dichos tratos. Antes es cabsa el dicho vedamiento que se saca mas pan e se conpra e guardan e retiene encamarado en los dichos reynos de Aragon e Valençia que sy el dicho vedamiento no estoviese ${ }^{79}$.

Las penas eran la requisa de las mercancías más cien azotes la primera vez, el destierro la segunda y la tercera el envío a galeras ${ }^{80}$. Los representantes municipales, ya fuese el alcaide ya los oficiales concejiles, se erigen como la voz de los habitantes del Marquesado y su testimonio supone toda una apología de los intereses de la comunidad frente a los designios arbitrarios del monarca. No podemos perder de vista que existiera un verdadero interés general por la conservación de la región. Pero no menos cierto fue que estas oligarquías eran las más beneficiadas del intercambio de productos ya que, al fin y al cabo, eran los que realmente tenían el trigo, la carne y los demás productos con los que se comerciaba. Eran, por lo tanto, los dueños de las mercancías que llevaban las carretas que dirigían los trajineros, la mayoría de las veces meros jornaleros que sólo ponían el vehículo porteador.

A pesar de las quejas, la Corona siguió con su propósito de castigar los fraudes, bajo la excusa de que la saca de pan encarecía los precios en el reino y los pobres sufrían mucho. Las Cortes habían continuado con la política del vedamiento de las sacas, algo que no escapaba a la crítica de las poblaciones del Marquesado. Éstas se quejaban de intereses ocultos por parte de los procuradores, y sin duda, no debían estar muy desencaminadas. Por el Marquesado hablaba Murcia, que siempre estuvo muy lejos de defender los intereses de las poblaciones del norte. El mantenimiento de la veda permitía proteger los intereses de los ganaderos y productores de la capital frente a la injerencia de productos exteriores y asegurarse, al mismo tiempo, el abastecimiento de la ciudad, independientemente de las circunstancias que pudiesen concurrir en las localidades del Marquesado. Además, comprobamos que la Corona hacía un uso de las rentas como pago de fidelidades por encima de los intereses generales del reino:

\footnotetext{
${ }^{79}$ Por todo ello, pedían la suspensión del vedamiento y, sobre todo, que se guardase el derecho de la unión. AGS, Diversos de Castilla, Memoriales, leg. 201, exp. 8, s.f.

${ }^{80}$ El juez, Juan Fernández de Pinilla encontró culpables a Salvador Bonete Gras, Alonso de Iniesta, Juan Rodríguez, mozo de mosen Martín, Francisco de Pradas, Martín Fernández, Alonso Martín, Martín Soriano, Luis de Pradas, Damián Bonete, Juan Bonete, Fernando de Pradas, Juan de Chinchilla, Martín de Segorbe, Juan Merino, criado de doña Isabel, Miguel Sánchez criado de Alonso Bolniches, Antonio, hijo de Esteban de Egea, García Ochoa, hijo de Pedro Ochoa, Cristóbal Fernández, criado de Antonio, Juan Gil Gómez Tortosa, vecinos todos de Almansa. Cada uno de ellos llevaba una carretada de trigo, que contenía cada una quince fanegas. No acuden a sus llamamientos por los que los declara reos y culpables. La condena fue de cien azotes, las mulas perdidas y la confiscación de las quince fanegas de trigo. Por cada fanega un ducado de oro. Además debían pagar el salario del licenciado (ochenta días). AGS, Diversos de Castilla, Memoriales, leg. 220, doc. 52, s.f.
} 


\begin{abstract}
pues otra cosa no pueden hazer [comerciar con Valencia] para sustentar sus vidas y para pagar los pechos y derechos a vuestra magestad, [la permanencia de la prohibición de las sacas] seria asolar y destruyr la dicha provinçia y en ello vuestra magestad no seria servido ni su real camara aprovechada, porque hago saber a vuestra majestad que todo lo que se confisca en aquella provinçia a la camara de vuestra majestad por razon de aver sacado las dichas cosas vedadas an respeto y tocan a Garçia de Avila, recadador de vuestra majestad [...] No se confia por aquella provincia que, constandole a vuestra majestad, tenga por bien destruyr ocho o diez mill vasallos y muy fidelisimos al serviçio de vuestra magestad por enriquecer vn su recadador ${ }^{81}$.
\end{abstract}

Se hace difícil entender la Corona, o la administración "central" de la monarquía en este momento, como los representantes de una identidad nacional. La propia monarquía se debatía en multitud de relaciones y servicios con otras esferas de poder (elites locales, poderes eclesiásticos, magnates...) en una conjunción de intereses y apoyos mutuos. La construcción de una monarquía autoritaria se construía, paradójicamente, sobre el consenso y la negociación. En el entramado de esas relaciones, la hacienda real jugó un papel decisivo. Esclarecedoras son las palabras de David Alonso quien afirma que la creación del Consejo de Hacienda por Carlos V, relacionado con las reformas de tesorería, no respondía a la búsqueda de una mayor racionalidad en el gobierno de la hacienda. Sencillamente, se trataba de sobrevivir en el trono consiguiendo una fidelidad vinculada al servicio económico, en un claro ejemplo de que la institucionalización que experimentó el gobierno de la monarquía tras las Comunidades no respondía a criterios "estatales"

\title{
6. CONCLUSIONES
}

El comportamiento de los reinos de Murcia y Valencia a lo largo de la Baja Edad Media, y de algunas de sus regiones en particular, nos ejemplifica, entre otras muchas cosas, tres puntos sobre los cuales se ha querido reflexionar en este artículo. En primer lugar, el componente histórico que toda identidad posee. Pero al referirnos a histórico no lo hacemos desde la tradicional argumentación decimonónica que nos ilustra el pasado glorioso de las regiones para adoctrinar en una forma de ser determinada mostrando los sacrificios realizados por nuestros antepasados. Esos esfuerzos y el simple hecho de que lo que siempre ha sido así no puede romperse por un capricho arbitrario y coyuntural parecen mostrarse como argumentos de peso para que la historia tenga que ser enseñada como parte fundamental en la formación de los ciudadanos. El carácter histórico de las identidades viene dado, por el contrario, porque todo hecho se ve inserto en una realidad determinada que lo condiciona y a la cual pretende dar respuesta. La explicación y el análisis de la identidad desde la perspectiva histórica debe ir encaminada a la comprensión del contexto que generó las respuestas dadas por unas comunidades para favorecer y mantener la convivencia dentro de su seno. Pero las circunstancias cambian a lo largo del tiempo y, por tanto, la definición que tienen de sí los individuos y las comunidades. Cuando hablamos de que las identidades no pueden ser esenciales no se niega la permanencia de elementos a lo largo del tiempo ya que la experiencia de cada comunidad, de cada individuo, marca una trayectoria

\footnotetext{
${ }^{81}$ AGS, Diversos de Castilla, Memoriales, leg. 220, doc. 52, s.f.

${ }^{82}$ David Alonso, Fisco, Poder y Monarquía en los Albores de la Modernidad. Castilla 1504 1525, Valladolid, 2009.
} 
dependiente en el sentido de que esa experiencia posiciona, condiciona, a los implicados a una toma de acciones en el futuro. Pero en ningún momento, la dependencia de la trayectoria la inmoviliza en un sentido claro y rectilíneo porque nuestros intereses no se ven sometidos a un único elemento que nos permita definirnos y que, por tanto, rija nuestras actuaciones en función a las experiencias previas que nos definen. Esto nos da pie a resaltar el segundo de los puntos sobre el que hemos tratado. La frontera se puede utilizar para definirse precisamente porque no se es como el vecino, quien puede estar dispuesto a provocar la ruina del reino en el momento de menor descuido. Sin embargo, el comportamiento de comunidades insertas dentro de las fronteras de los reinos de Murcia y Valencia muestran sentimientos antagónicos hacia los reinos vecinos y respecto a otras comunidades de sus propias unidades políticas. Es por tanto interesante comprobar la diferente visión que se posee sobre lo que de verdad ayuda a mantener el bien común de un reino, y que no deja sino de definir la realidad regional de las comunidades. Las percepciones de las comunidades de a quién debían fidelidad, qué conformaba la base de su cultura, qué les permitía rechazar o aceptar elementos culturales o la defensa de los mismos está en circunstancias tan coyunturales como la guerra, la fiscalidad o el comercio, las cuales introducen elementos que van más allá de la simple esfera de lo político y lo jurídico.

$\mathrm{Y}$ en tercer lugar, podemos comprobar que no existe una suplantación de identidades por medio de la consolidación de realidades regnícolas que consigan homogeneizar al colectivo de sus súbditos por medio de códigos jurídicos o políticas de deportación y colonización de las tierras. No se posee una escala de identidad que nos marque en qué grado se es más una cosa que otra. La identidad común como hispanos basada en un sustrato cultural común alentado por reconstrucciones históricas desde las cancillerías regias y episcopales tuvo que convivir en igual grado con la identidad común como súbditos de unos reinos diferentes unos de otros. Y es más, esta idea tan común en nuestra actual visión de la identidad necesariamente enmarcada dentro de unos esquemas territoriales fijos tuvo que jugar con otras nociones particulares de identidad (familia, grupo, vecindad) que condicionaron la actuación y fidelidad de los individuos en igual grado de intensidad. La contradicción entre las diversas categorías que ayudan a definirnos, es decir, las identidades de configuran nuestra identidad, son demasiado importantes para ser ignoradas en aras a proyectos identitarios de talante general o superior. Incluso las cancillerías regias mostraban una idea contradictoria entre los intereses de la corona como institución particular y el bien general de sus territorios. Jugaba con dos mensajes contradictorios y paradójicos. Por un lado proclamaban la necesidad de la unión como legitimación de su naturaleza y, al mismo tiempo, imponía una fragmentación, con lo que ello implicaba de definición para las comunidades, necesaria para la obtención de recursos y mantenimiento de fidelidades. En el caso del reino de Murcia, la capital del reino se enfrentó a las tierras septentrionales del Marquesado en defensa de sus intereses económicos, cada una desde posiciones contradictorias en referencia al sentimiento de unidad de los reinos hispanos. Murcia defendía a principios del siglo XVI una Monarquía Hispánica plagada de fronteras donde se primaba la tradición medieval. Por su parte, el Marquesado pedía una nueva realidad espacial más abierta asentada en una monarquía común hispana. La necesidad de la corona de obtener apoyo en las cortes casi siempre decantó las decisiones regias a favor de las ideas defendidas por Murcia. 
El reino de Murcia en la Baja Edad Media
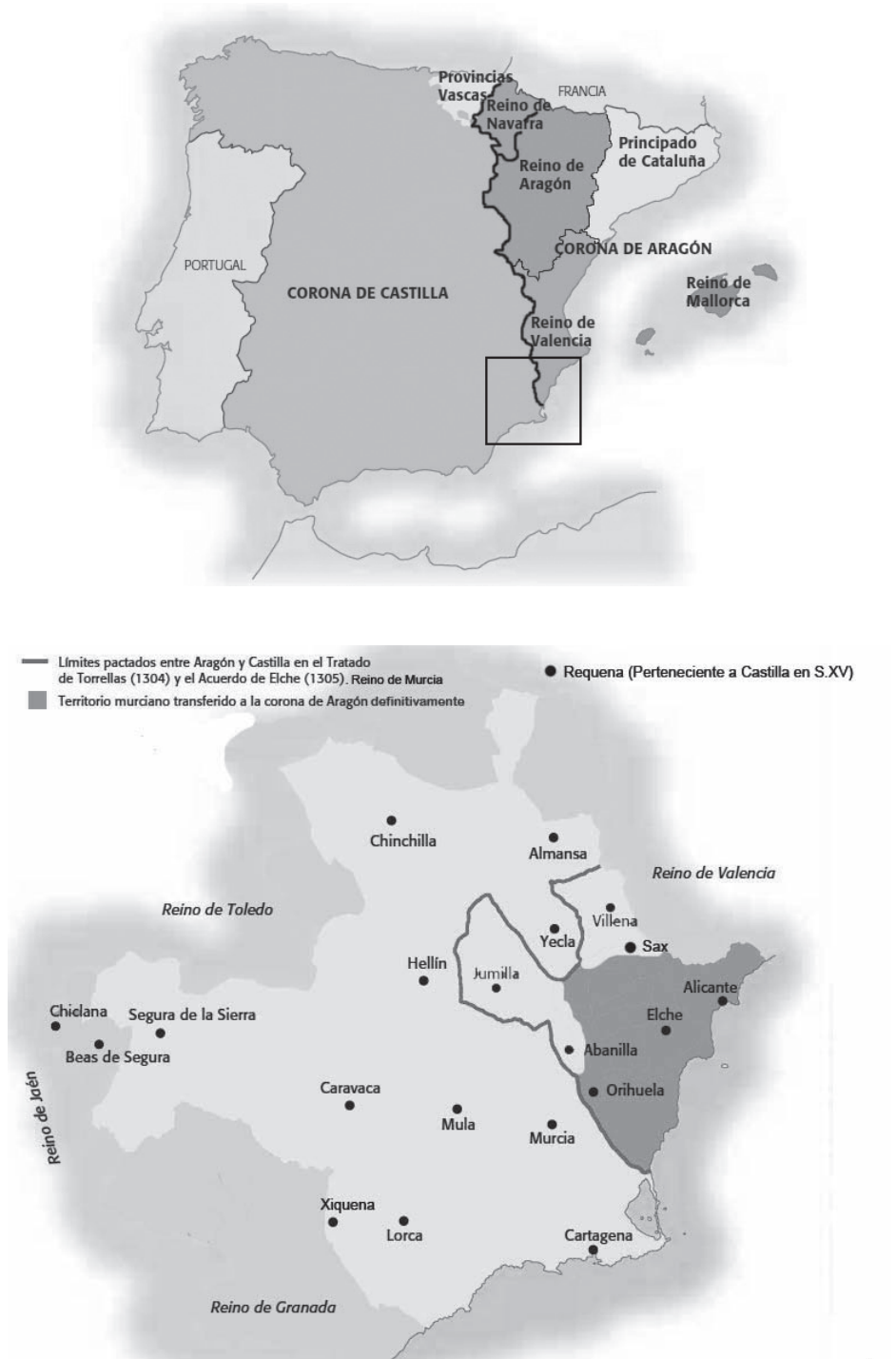

Fuente: M. RodRíGUEZ LLOPIS, Atlas Histórico Ilustrado de la Región de Murcia y su Antiguo Reino, Murcia, 2007, p. 107. Modificado por el autor.

Fecha de recepción del artículo: Agosto 2010

Fecha de aceptación y versión final: Febrero 2011 